\title{
A RESPOSTA DA MEMÓRIA ÀS PERDAS IRREPARÁVEIS
}

Ana Zandwais ${ }^{1}$, Maria Cleci Venturini ${ }^{2}$ e Verli Petri da Silveira ${ }^{3}$

A perda de um colega muitas vezes nos permite questionar quem somos e o que fizemos ao longo de nossa trajetória de intelectuais, onde a vida e o trabalho se mesclam de tal forma que o trabalho passa a transformar-se em vida, passando até mesmo a desafiá-la, não obstante os limites de toda ordem que se apresentam diante de nós.

É a partir deste contexto que nos propomos a trazer à nossa memória a imagem de Carme Regina Schons, que veio a falecer durante o mês de julho de 2015.

Carme Regina, que foi ao longo de vinte anos docente do Curso de Letras da Universidade de Passo Fundo, desenvolvendo atividades de pesquisa e docência nos Cursos de Graduação e de Pós-Graduação nessa IES e concluiu sua formação acadêmica na Universidade Federal do Rio Grande do Sul.

Durante a realização do Mestrado já tomava posições que possibilitavam a ela compreender que as escolhas da área de trabalho em que queria aprofundar-se - os estudos discursivos, a Análise do Discurso com ênfase em questões materialistas - não eram casuais e movidas apenas por uma curiosidade intelectual.

Mais tarde, a escolha dos temas a serem pesquisados viria também a comprovar o que ela buscava através do conhecimento intelectual. Durante o Mestrado, a escolha por investigar as condições de formação do Movimento Anarquista, durante a Primeira República, buscando analisar como as práticas e os discursos das Associações operárias, através de articulações entre a tendência anarco-sindicalista e as lideranças operárias, as quais vieram a transformar as condições de luta e a realidade de vida dos operários, apontava para o perfil de uma pesquisadora voltada para questões sociais e discursivas, tomadas sob uma perspectiva histórica, mas sobretudo voltadas para a trajetória de vida e de lutas das forças sociais, das parcelas marginais da sociedade.

1 Doutora em Lingüística e Letras pela PUCRS. Professora Titular do Instituto de Letras da UFRGS.

2 Doutora em Estudos Linguísticos pela UFSM. Atualmente é professora da Universidade Estadual do Centro-Oeste.

3 Doutora em Letras pela UFRGS e pós-doutora na Universidade Estadual de Campinas. Atualmente é professora associada da UFSM. 
A seguir, durante sua trajetória intelectual no Doutorado, Carme busca investigar o processo de organização da classe trabalhadora durante o regime de governo Vargas, analisando as contradições entre o projeto político de um governo de feição populista, suas ações e discursos em prol da emancipação dos trabalhadores brasileiros, e as formas de "domesticação" impostas às Associações sindicais e movimentos organizados que lutaram pela conquista de direitos e por um processo de organização política que respondesse aos interesses dos diferentes segmentos operários no país. Questão histórica e tão atual.

É importante trazer para o presente a memória de que mesmo quando desafiada pela doença, Carme respondia aos limites que seu corpo lhe impunha, produzindo intelectualmente, com a convicção de que sabia qual era o seu papel e, ao mesmo tempo, com a humildade daqueles que dão sem esperar nada do dia de amanhã, sem contar com uma participação efetiva na "colheita dos frutos." Mas os frutos ficaram, ainda que nem sempre ela pudesse ter consciência plena da dimensão de seu trabalho, de suas contribuições intelectuais; para citar alguns mais importantes: o livro intitulado "Saberes Anarquistas: reiterações, heterogeneidades, rupturas", publicado pela Editora da Universidade de Passo Fundo, em 2000, "Questões de escrita", organizado com Tânia Rosing e publicado pela Ed. UPF, em 2005; "Língua, Escola e Mídia”, livro organizado juntamente com Ercília Ana Cazarin e publicado pela Ed. UPF em 2011; inúmeros artigos publicados em Revistas acadêmicas de todo país, tais como: "O Estado e a propriedade: um acontecimento no movimento anarquista”. In: Revista Ensaios ( $n^{\circ}$ 12) Porto Alegre, Ed. Sagra-Luzzatto, 1999, p.88-121; "Quem é o sujeito no espelho da gramática?” In. Revista Desenredo. Passo Fundo, Ed. UPF, PPGL/UPF, 2009, p.170-181; "Leitura e civilidade: um estudo discursivo de práticas de silenciamento pela violência "costurada" no corpo infantil". In: Revista Organon ( ${ }^{\circ} 48$ ). Porto Alegre, Instituto de Letras da UFRGS, 2010, p.183-204; "Diante da lei aflição e aprisionamento ao processo", publicado em co-autoria com Lucas de Paula na Revista Rua (v.2). Campinas, Ed. da Unicamp, 2013, p.131-149; "O nome da língua: processos de institucionalização da língua brasileira e memória”, publicado na Letras (UFSM), em 2013.

A doença e mesmo seu desaparecimento não interromperam a produção de Carme. A Revista Acta Sientiarum, v. 37, no. 2, 2015, publicou em sua última edição o texto "Sociedade, corpo e relação subjetiva", em que a pesquisadora, como vinha fazendo há algum tempo, trata do corpo numa dimensão discursiva, o corpo como linguagem, que produz subjetividade. 
Para ela, "a linguagem do corpo também é atravessada pela ideologia, pelo jogo de forças, que permite desdobramentos de discursos-imagens, constitui memórias e produz silenciamentos de determinadas práticas" (p. 180).

O gesto analítico de Carme, em seu último texto, realiza-se por meio de três textos-imagens, o da estátua da Praça da República em Paris, com véu islâmico, durante o protesto da Associação "Nem putas, nem submissas"; o de Michael Jackson, em 2011, com vestes típicas de mulheres islâmicas, o da Juventude Socialista da Espanha: "Bendita camisinha que tira a aids do mundo", em que funcionam em um mesmo lugar uma hóstia e uma casinha, ambas nas mãos do padre. Carme destaca que não se trata de imagens, somente, mas que discursos-imagens resultantes do "ato de projetar uma imagem lembram/rememoram outras imagens. É no intervalo existente entre a imagem produzida e essas outras imagens que sentidos vão se sustentando".

As análises permitiram-lhe dizer que "o que o corpus analisado nos convida a perceber é a poeira que paira sobre os corpos. Essa poeira é diariamente depositada pelas vestes de práticas político-discursivas". Encerra, assim, seu derradeiro texto (conhecido e publicado), destacando, sempre a resistência, os silêncios e os entrelaçamentos, tão caros à sua obra e ao seu percurso.

Uma pesquisadora, entretanto, não se faz só de obras, ela se constrói também pelas práticas. Vale destacar a Carme, professora visitante na UNICENTRO/PR, ministrando a disciplina "Poéticas do silenciamento", na qual, assim como nos textos apresentados/revistados como "a resposta da memória às perdas irreparáveis", ela foi/será uma 'presença na ausência', como o rastro de quem literalmente incorporou/praticou a resistência e a persistência, em conferências, em palestras, em mesas redondas, em bancas e em aulas, porque, para ela, diálogo, pesquisa e docência metaforizavam a vida e retardavam a morte.

E pelo desejo sempre vivo de homenagear a quem tanto nos presenteou com sentimentos, conselhos, palavras, realizou-se o primeiro evento acadêmico em Homenagem a Carme Regina Schons, no dia 31 de agosto de 2015, na UFRGS, no mesmo auditório em que tantas vezes a ouvimos falar. Foi uma Jornada de Trabalho digna da homenageada, pois nela reuniram-se leitores-admiradores da Carme: ex-alunos, colegas, professoras... Nossa homenagem, então - parafraseando o que escreveu Eni Orlandi no prefácio do livro que publica em homenagem a Michel Pêcheux - é cotidiana e consiste em ler e compreender, com o entusiasmo de quem sempre pode descobrir algo de novo nas entrelinhas dos textos de Carme. 
A mesa-redonda composta pelas professoras Ana Zandwais, Gesualda Rasia e Florence Carboni, conduziu a todos por um trajeto de leitura novo em direção à Tese de doutorado e à Dissertação de mestrado de Carme, o que atualizou saberes da ordem do 'já-lá. Tal mesa teve como debatedora a professora Verli Petri, representando o Laboratório Corpus, da UFSM, um espaço que teve Carme como forte presença, importante interlocutora em eventos, bancas e publicações. Neste evento, o papel da debatedora foi também o de homenagear Carme, mas, sobretudo, o de destacar o quanto ainda está "a ler" nas palavras dela e nas entrelinhas.

A re-leitura da Tese, proposta pela colega Gesualda, nos fez refletir sobre a importância de ouvir o outro, exercício de humildade e generosidade que a Carme nos ensinou. A mesma Carme que lutou incansavelmente para construir um lugar na e para a prática política. Para a Carme, e isso aparece na Tese, é preciso pensar, ouvir e produzir outras narratividades. Dez anos após a escritura da Tese, a história e a teoria continuam sendo de grande pertinência. $\mathrm{O}$ objeto discursivo em estudo remonta ao início do século XX, mas nos parece tão atual: a migração é uma prática social atual, ainda tão problemática quanto no passado. A leitura realizada por Gesualda explicita muito bem a tomada de posição da Carme: a mulher, a pesquisadora, a professora, sujeito que se indigna com as injustiças, injúrias ou qualquer tipo de violência física ou simbólica que se pratique nesse mundo. Ao finalizar, já tomada por forte emoção, Gesualda nos convidou a mergulhar na complexidade que engendra a compreensão de quem foi Carme Schons, isso se dá pelas relações que ela manteve com a arte: de bem falar, de bem escrever, de metaforizar em texto, em discurso e em telas.

Florence Carboni destacou a força presente na luta de Carme Schons pela vida e pelo que acreditava, nos conduzindo ao mais profundo desejo de ser sujeito de sua própria história, do início até o final. De fato, cada um só pode falar do seu próprio lugar, é aí que se instala o evento único, seja na vida, seja na pesquisa. É preciso produzir com responsabilidade, seja na vida pessoal, seja na pesquisa, seja na arte: eis o legado de Carme Schons. Florence destaca também, o nosso modo de vida cotidiano de nos fazermos, às vezes, tão próximos e, ao mesmo tempo, tão distantes, já que a força da fragmentação, própria de políticas e espaços acadêmicos, nem sempre nos conduz a ter consciência de que não lemos os textos uns dos outros. E as perdas incontornáveis, como a de Carme, por outro lado, nos permitem compreender como se fazem necessárias reuniões de pessoas para lerem os textos uns dos outros, como aconteceu no dia desta homenagem.

Ana Zandwais, que foi orientadora de mestrado e de doutorado, interlocutora de Carme Schons por excelência, propôs uma releitura da Disser- 
tação "Saberes Anarquistas: reiterações, heterogeneidades, rupturas", reflexão produzida em meados dos anos 1990. Todos tomados pela emoção perguntavam-se silenciosamente: o que significa a orientadora lendo, quase 20 anos depois, a Dissertação de uma orientanda? E mais do que isso: propondo uma leitura de construção teórica e analítica mais atual do que nunca?! A professora Ana teve a oportunidade de demonstrar como tal Dissertação carregava em seu bojo as características de uma tese de Doutoramento, pois propunha uma leitura singular para as noções de discurso, história e acontecimento. Tais reflexões nos conduziram a refletir sobre o que faz com que um pesquisador seja reconhecido como um intelectual. Talvez a trajetória de vida e de pesquisa de Carme Schons seja um belo exemplo disso, afinal de contas, sabemos que "juntar as letras $\mathrm{c}+\mathrm{a}+\mathrm{r}+\mathrm{m}+\mathrm{e}$ é muito mais que se chegar ao simplesmente Carme. Juntar as letras é constituir sentidos para o que a Carme representa para todos nós como profissionais das Letras" (Scherer ${ }^{4}, 2011$, p. 249).

4 Da obra "Língua, escola e mídia", organizada por Carme Regina Schons e Ercília Ana Cazarin. Organon, Porto Alegre, v. 30, n. 59, p. 227-231, jul/dez. 2015. 